\title{
"TRABALHADORES DO CONHECIMENTO" NA IMIGRAÇÃO INTERNACIONAL: UM ESTUDO SOBRE A IMIGRAÇÃO DOS PAÍSES DO MERCOSUL PARA O BRASIL
}

Jóice Domeniconi ${ }^{1}$

Rosana Baeninger ${ }^{2}$

\section{RESUMO}

A compreensão dos movimentos migratórios no século XXI envolve o estudo de diferentes modalidades migratórias, como a migração de trabalhadores com alto nível educacional e ocupações de grande representatividade econômica, política e social. Assim, é importante pensar um novo panorama econômico internacional, que reflete uma maior intensidade da internacionalização do capital e da mobilidade da força de trabalho (SASSEN, 1988) e gera efeitos nas sociedades receptoras desses fluxos, sobretudo, quando barreiras físicas, políticas e econômicas são retiradas em prol da "livre circulação de bens, serviços e fatores produtivos", como no Mercado Comum do Sul (MERCOSUL.GOV). Busca-se, portanto, analisar os recentes fluxos migratórios de uma parcela qualificada de imigrantes oriundos dos países membros do MERCOSUL (Argentina, Uruguai, Paraguai e Venezuela) com destino ao Brasil a partir da discussão e atualização das ocupações da classe criativa/trabalhadores do conhecimento de Mello (2007). Adota-se, assim, a denominação de Florida (2004) de núcleo supercriativo e de profissionais criativos. Consideram-se, ainda, os "espaços da migração" envolvidos nessa dinâmica e as relações próprias da divisão internacional do trabalho estabelecidas entre essas localidades (BAENINGER, 2013). Serão utilizadas informações do mercado de trabalho formal brasileiro da RAIS, Censo Demográfico e Sistema Nacional de Cadastro e Registro de Estrangeiros, MJ-PF.

Palavra Chave: Imigração internacional qualificada, Trabalhador do Conhecimento e MERCOSUL

\section{INTRODUÇÃO}

A compreensão dos movimentos migratórios no século XXI envolve o estudo de diferentes modalidades migratórias, entre elas a migração de trabalhadores com alto nível educacional e ocupações de grande representatividade econômica, política e social. Assim, é importante levar em consideração um novo panorama econômico internacional, o qual reflete uma maior intensidade da internacionalização do capital e da mobilidade da força de trabalho (SASSEN, 1988)

\footnotetext{
${ }^{1}$ Mestranda em Demografia - IFCH-UNICAMP e pesquisadora no Observatório das Migrações em São Paulo-NEPO/UNICAMP. E-mail: joicedomeniconi@outlook.com

2 Professora Livre-Docente do Departamento de Demografia e do Núcleo de Estudos de População Elza Berquó. Coordenadora do Observatório das Migrações em São Paulo (NEPO-UNICAMP) E-mail: baeninger@nepo.unicamp.br.
} 
e gera efeitos nas sociedades receptoras desses fluxos, sobretudo, quando barreiras físicas, políticas e econômicas são retiradas em prol da "livre circulação de bens, serviços e fatores produtivos", como no Mercado Comum do Sul (MERCOSUL) (MERCOSUL).

Nesse contexto, o artigo visa discutir os recentes fluxos migratórios internacionais de uma parcela qualificada de imigrantes oriundos dos países membros do MERCOSUL (Argentina, Uruguai, Paraguai e Venezuela) com destino ao Brasil a partir da discussão e atualização das ocupações da classe criativa/trabalhadores do conhecimento de Mello (2007) Adota-se, para tanto, a denominação de Florida (2004; 2014) de Núcleo Super Criativo, Profissionais Criativos e da categoria Outros.

Busca-se, portanto, compreender e identificar o grupo formado por imigrantes internacionais qualificados, sua distribuição, formação e inserção no mercado de trabalho nacional. Dessa forma, com base no cenário da economia transnacional no país e na entrada desse grupo particular de imigrantes internacionais, é que este trabalho pretende analisar o atual movimento imigratório internacional de mão de obra qualificada oriunda do MERCOSUL para o Brasil. Leva-se em conta, ainda, os "espaços da migração" envolvidos nessa dinâmica e as relações próprias da divisão internacional do trabalho estabelecidas entre essas localidades (BAENINGER, 2013).

Para tanto, serão utilizadas as informações do mercado de trabalho formal do estado de São Paulo contidas na base de dados da Relação Anual de Informações Sociais do Ministério do Trabalho e Emprego (RAIS). Ademais, uma parte importante dos imigrantes encontra-se fora da esfera formal de trabalho ou atua como autônomo e, portanto, não será contabilizada na RAIS.

Essa análise visa, portanto, apresentar um panorama geral da migração de trabalhadores qualificados, altamente escolarizados e com ocupações de grande importância social, econômica e política para a sociedade, no contexto de bloco comercial, como o MERCOSUL, em anos recentes.

\section{UMA BREVE DISCUSSÃO SOBRE O CONCEITO DE TRABALHADORES DO CONHECIMENTO}

Para compreender qual o perfil desses imigrantes internacionais qualificados considerados enquanto trabalhadores do conhecimento, identificar suas demandas, interesses e as relações nas quais estão envolvidos, seu nível educacional e qualificação, analisar sua mobilidade espacial para o Brasil, por fim, determinar em que ocupações esses indivíduos estão inseridos no mercado de trabalho nacional, é importante, em primeiro lugar, definir tal conceito a partir do debate já estabelecido por outros autores, como Castells (1996, 1999), Drucker (2001), Florida (2004, 2014) e Mello (2007).

Castells $(1996,1999)$ denomina os trabalhadores do conhecimento a partir dos aspectos relacionados à sua formação educacional e acadêmica. São os indivíduos com maior número de anos de estudo presentes numa determinada população. Isso se deve ao fato de que uma sólida formação educacional, com, ao menos, um grau universitário, é fundamental para o desenvolvimento de uma carreira como trabalhador do conhecimento. 


\section{SEMINÁRIO DE PESQUISA EM CIÊNCIAS HUMANAS - SEPECH \\ Humanidades, Estado e desafios didático-científicos \\ Londrina, 27 a 29 de julho de 2016}

Drucker (2001), já nos anos 1960, defendia a ideia de que os trabalhadores do conhecimento não chegariam a ser a maioria dentro da sociedade do conhecimento que se formava, mas, ainda assim, passariam a constituir uma parcela significativa (e com poder econômico e político) da força de trabalho e da população, principalmente em países desenvolvidos.

Florida $(2014)^{3}$, por sua vez, utiliza o conceito de trabalhadores do conhecimento de forma a abordar a perspectiva de ascensão de uma nova classe social, a "classe criativa", constituída por indivíduos de diferentes áreas do conhecimento e com características particulares que os permitem exercer um papel dominante na sociedade, sobretudo, devido ao importante papel econômico e financeiro que exercem (FLORIDA, 2014). O autor chama de classe criativa em seu estudo sobre os Estados Unidos "um grande número de trabalhadores do conhecimento, analistas simbólicos e trabalhadores profissionais e técnicos [...] pessoas que agregam valor econômico por meio de sua criatividade" (FLORIDA, 2014, posição 490) ${ }^{4}$. Para Florida, a base dessa classe seria, principalmente, econômica, de modo a "[...] sustentar e informar seus membros social e culturalmente, assim como, suas escolhas de estilo de vida [...]" (Ibid. 2014, posição 302) ${ }^{5}$. Ademais, tendo em vista a importância da criatividade e da inovação para o processo de crescimento econômico de uma região, ressalta-se o poder que essa classe exerceria na sociedade no que diz respeito à influência política e econômica (FLORIDA, 2014).

A partir disso, Florida (2014) apresenta o que seria um núcleo "duro" e uma esfera mais "fluida" com possíveis interrelações na estrutura ocupacional desses profissionais. Assim, o núcleo da classe criativa, denominado Super Creative Core incluiria os trabalhadores do conhecimento de fato, ou seja, profissionais que ocupariam as mais altas hierarquias de trabalho criativo.

$\mathrm{O}$ autor define, ainda, o que seria uma esfera mais fluida dentro das ocupações inseridas na classe criativa na qual estariam inseridos os Creative Professionals. Esses trabalhadores, ainda que normalmente apresentem um alto nível de educação formal e de capital humano como os Super Creative Core, não costumam atuar no processo criativo de desenvolvimento tecnológico, mas no desenvolvimento e criação de conhecimento criativo voltado para a resolução de problemas específicos (FLORIDA, 2004 apud MELLO, 2007).

Nesse sentido, os profissionais criativos seriam advogados, contadores, administradores de empresas e demais trabalhadores que dão suporte ao desenvolvimento, pesquisa e inovação tecnológica. É importante, portanto, que esses profissionais sejam capazes de "[...] pensar por conta própria, aplicar ou combinar abordagens comuns de forma inusitada para resolver diferentes situações, exercer bom

\footnotetext{
${ }^{3}$ A referência citada trata de um e-book e, portanto, será utilizada a posição da citação no texto e não as páginas, visto que essas não estão disponíveis nesse tipo de mídia. FLORIDA, R. (e-book) The rise of the creative class: and how it's transforming work, leisure, community \& everyday life. New York: Basic Books, 2014.

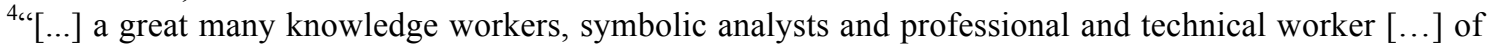
people who add economic value through their creativity" (Tradução livre) (FLORIDA, 2014, posição 490).

5 “[...] underpins and informs its member's social, cultural and life styles choices [...]" (Tradução livre) (FLORIDA, 2014, posição 302).
} 


\section{SEMINÁRIO DE PESQUISA EM CIÊNCIAS HUMANAS - SEPECH \\ Humanidades, Estado e desafios didático-científicos \\ Londrina, 27 a 29 de julho de 2016}

senso em seus julgamentos" (FLORIDA, 2014, posição 924) ${ }^{6}$, ou seja, eles devem buscar sempre novas formas e métodos mais eficientes e criativos de realizar suas tarefas.

Logo, a estrutura da classe criativa de Florida (2014) inclui um Núcleo Super Criativo (Tradução Livre) formado por profissionais que exerçam ocupações relacionadas à computação e à matemática; à arquitetura e às engenharias; às ciências da vida, físicas e sociais; à educação, ao treinamento e à biblioteconomia; às artes, ao design, ao entretenimento, aos esportes e à mídia. E um grupo mais difuso, de Profissionais Criativos (Tradução Livre), os quais exercem ocupações relacionadas à administração e à gestão; aos negócios e às operações financeiras; ao sistema legal; à prática e à técnica dos cuidados à saúde; à gestão de vendas e ao atacado.

Mello (2007) por sua vez busca demonstrar a espacialização desse trabalhador do conhecimento em Campinas-SP e, para tanto, propõe a partir dos critérios de autores como Florida (2004) e com as informações do Código Brasileiro de Ocupações (CBO) ${ }^{7}$, o agrupamento a seguir, para identificar o trabalhador do conhecimento (Tabela 1).

Com base nessa metodologia, é possível estabelecer uma discussão e atualização das ocupações na classe criativa/trabalhador do conhecimento contemplando os imigrantes oriundos dos países membros do MERCOSUL para o Brasil. Adota-se, assim, a denominação utilizada por Florida (2004) de Núcleo Super Criativo e de Profissionais Criativos, as quais foram adaptadas ao padrão CBO por Mello (2007). O trabalhador do conhecimento, nesse trabalho, englobará, portanto, as três categorias abaixo indicadas.

\begin{tabular}{|c|c|c|c|c|}
\hline \multirow{3}{*}{$\begin{array}{l}\text { Código } \\
\text { de Base } \\
\text { CBO }\end{array}$} & \multirow{3}{*}{ Ocupação } & \multicolumn{3}{|c|}{$\begin{array}{ll}\text { Trabalhadores } & \text { do } \\
\text { Conhecimento } & \end{array}$} \\
\hline & & \multicolumn{2}{|c|}{ Classe Criativa } & \multirow{2}{*}{$\begin{array}{l}\text { Outro } \\
\text { s }\end{array}$} \\
\hline & & \begin{tabular}{|l|} 
Super \\
Criativos \\
\end{tabular} & \begin{tabular}{|l} 
Profissionai \\
s Criativos \\
\end{tabular} & \\
\hline 2011 & Profissionais de Bioenergia e Engenharia Genética & $\mathrm{X}$ & & \\
\hline 2012 & Profissionais de Metrologia & & $\mathrm{X}$ & \\
\hline 2021 & Engenheiros Mecatrônicos & $\mathrm{X}$ & & \\
\hline 2111 & Profissionais da Matemática & $\mathrm{X}$ & & \\
\hline 2112 & Profissionais da Estatística & $\mathrm{X}$ & & \\
\hline 2122 & Engenheiros em Computação-Desenv. Software & $\mathrm{X}$ & & \\
\hline 2123 & Especialista em Informática & $\mathrm{X}$ & & \\
\hline 2124 & Analista de Sistemas & $\mathrm{X}$ & & \\
\hline 2131 & Físicos & $\mathrm{X}$ & & \\
\hline 2132 & Químicos & $\mathrm{X}$ & & \\
\hline 2133 & Profissionais do espaço e da Atmosfera & $\mathrm{X}$ & & \\
\hline 2134 & Geólogos e Geofísicos & $\mathrm{X}$ & & \\
\hline
\end{tabular}

\footnotetext{
${ }^{6 ،}[\ldots]$ think on their own, apply or combine standard approaches in unique ways to fit different situations, exercise a great deal of judgment, and perhaps even try something radically new from time to time" (Tradução livre) (FLORIDA, 2014, posição 924).

${ }^{7}$ "Esta classificação descreve e ordena as ocupações dentro de uma estrutura hierarquizada que permite agregar as informações referentes à força de trabalho segundo as características que dizem respeito às funções, tarefas e obrigações do trabalhador e ao conteúdo de seu trabalho (conhecimentos, habilidades e outros requisitos exigidos para o exercício da ocupação)" (PARLERMO et al, 2015, p.27).
} 


\section{SEMINÁRIO DE PESQUISA EM CIÊNCIAS HUMANAS - SEPECH \\ Humanidades, Estado e desafios didático-científicos \\ Londrina, 27 a 29 de julho de 2016}

\begin{tabular}{|c|c|c|c|}
\hline 2140 & Engenheiros Ambientais e Afins & $X$ & \\
\hline 2141 & Arquitetos & $\mathrm{X}$ & \\
\hline 2142 & Engenheiros Civis e Afins & $\mathrm{X}$ & \\
\hline 2143 & Engenheiros Eletroeletrônicos e afins & $\mathrm{X}$ & \\
\hline 2144 & Engenheiros Mecânicos & $\mathrm{X}$ & \\
\hline 2145 & Engenheiros Químicos & $\mathrm{X}$ & \\
\hline 2146 & Engenheiros Metalurgistas e de Materiais & $\mathrm{X}$ & \\
\hline 2147 & Engenheiros de Minas & $\mathrm{X}$ & \\
\hline 2148 & Engenheiros Agrimensores e de Cartografia & $\mathrm{X}$ & \\
\hline 2149 & Engenheiros Industriais, de produção e segurança & $\mathrm{X}$ & \\
\hline 2151 & Oficiais de Convés & & $\mathrm{X}$ \\
\hline 2152 & Oficiais de Máquinas da marinha mercante & & $\mathrm{X}$ \\
\hline 2153 & Profissionais da Pilotagem aeronáutica & & $\mathrm{X}$ \\
\hline 2211 & Biólogos e afins & $\mathrm{X}$ & \\
\hline 2221 & Engenheiros agrossivilpecuários & $\mathrm{X}$ & \\
\hline 2251 & Médicos Clínicos & $\mathrm{X}$ & \\
\hline 2232 & Cirurgiões-Dentistas & $\mathrm{X}$ & \\
\hline 2233 & Veterinários e Zootecnistas & $\mathrm{X}$ & \\
\hline 2234 & Farmacêuticos & $\mathrm{X}$ & \\
\hline 2235 & Enfermeiros de Nível superior e afins & $\mathrm{X}$ & \\
\hline 2236 & Profissionais da Habilitação e Reabilitação & $\mathrm{X}$ & \\
\hline 2237 & Nutricionistas & $\mathrm{X}$ & \\
\hline 2311 & Professores de Nível Superior na Educação Infantil & & $\mathrm{X}$ \\
\hline 2312 & \begin{tabular}{|l} 
Professores de nível superior do ensino \\
fundamental de primeira a quarta série
\end{tabular} & & $\mathrm{X}$ \\
\hline 2313 & \begin{tabular}{|l}
$\begin{array}{l}\text { Professores de nível superior no ensino } \\
\text { fundamental de quinta a oitava série }\end{array}$ \\
\end{tabular} & & $\mathrm{X}$ \\
\hline 2321 & Professores do Ensino Médio & & $\mathrm{X}$ \\
\hline 2331 & Professores do Ensino Profissional & $\mathrm{X}$ & \\
\hline 2332 & Instrutores do Ensino Profissional & $\mathrm{X}$ & \\
\hline 2341 & \begin{tabular}{|l} 
Professores de matemática, estatística e \\
informática do ensino superior
\end{tabular} & & $\mathrm{X}$ \\
\hline 2342 & $\begin{array}{l}\text { Professores de ciências físicas, químicas e afins do } \\
\text { ensino superior }\end{array}$ & & $\mathrm{X}$ \\
\hline 2343 & $\begin{array}{|lccc|}\text { Professores de Arquitetura e } & \text { Urbanismo, } \\
\text { Engenharia, Geofísica e Geologia } & \text { do Ensino } \\
\text { Superior } & & & \end{array}$ & & $X$ \\
\hline 2344 & $\begin{array}{l}\text { Professores de ciências biológicas e da saúde do } \\
\text { ensino superior }\end{array}$ & & $X$ \\
\hline 2345 & $\begin{array}{l}\text { Professores na área de formação pedagógica do } \\
\text { ensino superior }\end{array}$ & & $\mathrm{X}$ \\
\hline 2346 & $\begin{array}{l}\text { Professores nas áreas de língua e literatura do } \\
\text { ensino superior }\end{array}$ & & $\mathrm{X}$ \\
\hline 2347 & Professores de ciências humanas do ensino superior & & $\mathrm{X}$ \\
\hline 2348 & \begin{tabular}{|l} 
Professores de ciências econômicas, \\
administrativas e contábeis do ensino superior
\end{tabular} & & $\mathrm{X}$ \\
\hline
\end{tabular}




\section{SEMINÁRIO DE PESQUISA EM CIÊNCIAS HUMANAS - SEPECH \\ Humanidades, Estado e desafios didático-científicos \\ Londrina, 27 a 29 de julho de 2016}

\begin{tabular}{|c|c|c|c|c|}
\hline 2349 & Professores de artes do ensino superior & & & $\mathrm{X}$ \\
\hline 2392 & Professores de Educação Especial & & & $\mathrm{X}$ \\
\hline 2394 & \begin{tabular}{|l|l|}
$\begin{array}{l}\text { Programadores, Avaliadores e Orientadores de } \\
\text { Ensino }\end{array}$ \\
\end{tabular} & & & $\mathrm{X}$ \\
\hline 2410 & Advogados & & $\mathrm{X}$ & \\
\hline 2412 & Procuradores e Advogados públicos & & & $\mathrm{X}$ \\
\hline 2422 & \begin{tabular}{|l|l|} 
Membros do ministério público/Promotores \\
Defensores Públicos e Afins
\end{tabular} & & $\mathrm{X}$ & \\
\hline 2423 & Delegados de polícia & & & $\mathrm{X}$ \\
\hline 2511 & $\begin{array}{l}\text { Profissionais em Pesquisa e Análise Antropológica } \\
\text { e Sociológica }\end{array}$ & $\mathrm{X}$ & & \\
\hline 2512 & Profissionais em Pesquisa e Análise econômica & $\mathrm{X}$ & & \\
\hline 2513 & $\begin{array}{l}\text { Profissionais em Pesquisa e Análise Histórica e } \\
\text { geográfica }\end{array}$ & $\mathrm{X}$ & & \\
\hline 2514 & Filósofos e cientistas políticos & $\mathrm{X}$ & & \\
\hline 2515 & Psicólogos e psicanalistas & & $X$ & \\
\hline 2516 & Assistentes sociais e economistas domésticos & & & $\mathrm{X}$ \\
\hline 2521 & Administradores de Empresas & & $\mathrm{X}$ & \\
\hline 2522 & Contadores e auditores & & & $\mathrm{X}$ \\
\hline 2523 & Secretários Executivos e Bilíngues & & & $\mathrm{X}$ \\
\hline 2524 & Profissionais de recursos humanos & & & $\mathrm{X}$ \\
\hline 2525 & $\begin{array}{|lll|}\begin{array}{l}\text { Profissionais da administração econômico- } \\
\text { financeira }\end{array} & \\
\end{array}$ & & $\mathrm{X}$ & \\
\hline 2531 & $\begin{array}{l}\text { Profissionais de Relações Públicas, Publicidade, } \\
\text { Mercado e Negócios }\end{array}$ & $\mathrm{X}$ & & \\
\hline 2611 & Profissionais do Jornalismo & $\mathrm{X}$ & & \\
\hline 2612 & Profissionais da Informação & $\mathrm{X}$ & & \\
\hline 2613 & Arquivologistas e Museólogos & $\mathrm{X}$ & & \\
\hline 2614 & Filólogos, intérpretes e tradutores & $\mathrm{X}$ & & \\
\hline 2615 & Profissionais da Escrita & $\mathrm{X}$ & & \\
\hline 2616 & Especialistas em editoração & $\mathrm{X}$ & & \\
\hline 2617 & $\begin{array}{l}\text { Locutores, Comentaristas e Repórteres de rádio e } \\
\text { televisão }\end{array}$ & $X$ & & \\
\hline 2621 & Produtores Artísticos e Culturais & $\mathrm{X}$ & & \\
\hline 2622 & Diretores de espetáculos e afins & $\mathrm{X}$ & & \\
\hline 2623 & Cenógrafos & $\mathrm{X}$ & & \\
\hline 2624 & \begin{tabular}{|l|l} 
Artistas visuais, desenhistas industriais e \\
conservadores-restauradores de bens culturais
\end{tabular} & $X$ & & \\
\hline 2625 & Atores & $X$ & & \\
\hline 2626 & $\begin{array}{l}\text { Músicos compositores, arranjadores, regentes e } \\
\text { musicólogos }\end{array}$ & $\mathrm{X}$ & & \\
\hline 2627 & Músicos intérpretes & $\mathrm{X}$ & & \\
\hline 2628 & $\begin{array}{l}\begin{array}{l}\text { Artistas da dança (exceto dança tradicional e } \\
\text { popular) }\end{array} \\
\end{array}$ & $\mathrm{X}$ & & \\
\hline 2629 & Designer de interiores de nível superior & $\mathrm{X}$ & & \\
\hline 2711 & Chefes de cozinha e afins & $\mathrm{X}$ & & \\
\hline
\end{tabular}




\section{SEMINÁRIO DE PESQUISA EM CIÊNCIAS HUMANAS - SEPECH \\ Humanidades, Estado e desafios didático-científicos \\ Londrina, 27 a 29 de julho de 2016}

Tabela 1. Classe Criativa/Trabalhador do Conhecimento e CBO

Fonte: Dados obtidos a partir de Mello (2007) e Código Brasileiro de Ocupações (CBO, 2002).

De maneira a compreender como a migração internacional desse grupo de trabalhadores do conhecimento, com base em Mello (2007), tem se dado para o Brasil, suas diferentes espacialidades e também as potencialidades de absorção dessa imigração, será necessário avaliar como se dá a inserção desses indivíduos no mercado de trabalho nacional, assim como, sua escolaridade, faixa etária e nacionalidades. Para tanto, serão utilizadas as informações do mercado de trabalho formal contidas na base de dados da RAIS ${ }^{8}$. No entanto, é importante levar em consideração que tais dados representam os vínculos ativos estabelecidos com as empresas e não o montante de imigrantes. Outra dificuldade presente em seu uso diz respeito a possíveis omissões, erros de preenchimento ou divulgação de dados fora do período de declaração por parte dos empregadores. Porém, como observam Palermo et al (2015), essas limitações têm sido superadas, principalmente, com a mudança do processo para meio magnético e pela internet a partir de 2000. Além disso, uma parte importante dos imigrantes encontra-se fora da esfera formal de trabalho, atua como autônomo ou em outras atividades sem regulamentação e carteira assinada, de modo que, não será contabilizada nessa base de dados.

Logo, busca-se apresentar uma discussão geral acerca da imigração para o Brasil de trabalhadores do conhecimento no contexto do MERCOSUL em anos recentes, ou seja, de uma mão de obra qualificada, altamente escolarizada e com ocupações de grande importância social, econômica e política para as sociedades de origem e de destino.

\section{MERCOSUL E A MIGRAÇÃO INTERNACIONAL}

De modo a estabelecer uma discussão acerca da migração dos países parte e associados do MERCOSUL para o Brasil é necessário em primeiro lugar compreender como se deu a formação dessa união aduaneira, quais foram os objetivos principais traçados no momento de sua constituição e os avanços já alcançados em favor da mobilidade dos trabalhadores do conhecimento.

Assim, tem-se que MERCOSUL foi criado em 1991 com base no Tratado de Assunção. Sua principal finalidade é promover a integração entre os países membros, Brasil, Argentina, Paraguai e Uruguai, ou seja, a livre circulação de bens, serviços e fatores produtivos, assim como, estabelecer uma Tarifa Externa comum (TEC), promover a adoção de políticas comerciais conjuntas para com terceiros Estados, agrupamentos de Estados ou mesmo a definição de posições em instâncias de debate regional ou internacional (MERCOSUL). Objetiva-se, ainda, coordenar políticas

\footnotetext{
${ }^{8}$ Os dados obtidos a partir da RAIS representam registros administrativos de responsabilidade do empregador e com periodicidade anual, além disso, há uma abrangência nacional (possível de ser desagregadas por país, grandes regiões, Unidades da Federação e municípios). As informações disponibilizadas representam em média $97 \%$ do universo do mercado formal brasileiro a partir de dados de estoque (número de empregos) e de movimentação da mão de obra empregada (contratações e desligamentos) com base na Consolidação das Leis do Trabalho (CLT) (PALERMO et al, 2015, p.19-21).
} 


\section{SEMINÁRIO DE PESQUISA EM CIÊNCIAS HUMANAS - SEPECH \\ Humanidades, Estado e desafios didático-científicos \\ Londrina, 27 a 29 de julho de 2016}

macroeconômicas e em setores específicos da economia e as legislações dos diferentes países em áreas de interesse.

É importante observar que o MERCOSUL visa promover um maior intercâmbio em âmbito regional e não apenas dentro do grupo de países membros. Sendo assim, considera-se a existência de Estados Associados. São eles: Bolívia (em processo de adesão ao bloco); Chile (desde 1996); Peru (desde 2003); Colômbia e Equador (desde 2004) e, por fim, Guiana e Suriname (desde 2013). Nesse contexto, observa-se que todos os países da América do Sul fazem parte atualmente do MERCOSUL, seja como Estados Partes ou Estados Associados (MERCOSUL).

Ao longo dos últimos 25 de existência do MERCOSUL algumas medidas foram adotadas com o objetivo de facilitar a maior integração econômica e política e, também, a mobilidade dos cidadãos entre os diferentes países integrantes do grupo em um contexto de abertura comercial. Cabe destacar acordos voltados à documentação para viagens $^{9}$; residência $^{10}$; seguridade social ${ }^{11}$ e à coordenação educacional ${ }^{12}$.

Assim, do ponto de vista do Brasil, "os imigrantes provenientes de países do MERCOSUL não precisam passar pelo processo administrativo de solicitar autorização de trabalho" ao Ministério do Trabalho e Emprego (MTE) ou a Coordenação Nacional de Imigração (CNIg) devido, justamente, aos acordos voltados à integração regional (PALERMO et al, 2015, p. 150).

\subsection{O MERCOSUL e os Imigrantes Profissionais do Conhecimento}

Para uma melhor compreensão dos imigrantes qualificados, aqui denominados de "imigrantes profissionais do conhecimento", foram selecionados os vínculos de trabalho ativos, para estrangeiros ${ }^{13}$ entre 10 e 65 anos ou mais de idade, registrados no mercado de trabalho formal do estado de São Paulo, que apresentassem uma escolaridade maior ou igual ao Ensino Superior Completo ${ }^{14}$ e segundo ocupações preestabelecidas na Tabela 1, acima. Cabe ressaltar que dentre as ocupações selecionadas estão incluídas aquelas referentes ao Núcleo Super Criativo; aos Profissionais do Conhecimento e também à categoria Outros, visto que as profissões

\footnotetext{
${ }^{9}$ Segundo a Decisão CMC n ${ }^{\circ} 14 / 11$ é dispensado o uso de passaportes ou visto para circulação de cidadãos dos países atuantes no MERCOSUL, basta apenas a apresentação de uma carteira de identidade nacional ou documento similar (MERCOSUL.GOV).

${ }^{10}$ Segundo a Decisão CMC n²8/02 os cidadãos originários de países parte ou associados possuem direito de residir e trabalhar nos demais países do grupo com requisitos mínimos de documentação e burocracia (MERCOSUL.GOV).

${ }^{11}$ Segundo a Decisão CMC n¹9/97 aos trabalhadores migrantes e suas famílias são garantidos os direitos referentes à seguridade social podendo ser contabilizado o tempo de serviço em outro país parte ou associado ao MERCOSUL em caso de aposentadoria, invalidez ou morte (MERCOSUL.GOV).

${ }^{12}$ Com base no Sistema de Acreditação Regional de Cursos de Graduação do MERCOSUL (ARCUSUL), no Sistema Integrado de Mobilidade (SIMERSUL) e em diferentes protocolos, busca-se promover a revalidação dos graus acadêmicos de diferentes níveis dos cidadãos de países membros e associados ao MERCOSUL de modo a favorecer a mobilidade de profissionais que possam de fato atuar no mercado de trabalho (MERCOSUL.GOV).

${ }^{13}$ Foram considerados os vínculos ativos de indivíduos de nacionalidade argentina, boliviana, chilena, colombiana, equatoriana, paraguaia, peruana, uruguaia e venezuelana. No entanto, a RAIS não fornece de forma discriminada os vínculos para nacionalidade guianesa e surinamesa.

${ }^{14}$ Foram selecionados trabalhadores com Ensino Superior Completo, Mestrado e Doutorado.
} 


\section{SEMINÁRIO DE PESQUISA EM CIÊNCIAS HUMANAS - SEPECH \\ Humanidades, Estado e desafios didático-científicos \\ Londrina, 27 a 29 de julho de 2016}

consideradas nesse último grupo dão suporte às duas primeiras. Além disso, na categoria Outros estão incluídos profissionais da área educacional, fundamentais para a formação de profissionais que atuarão nas ocupações das demais categorias.

A partir disso, o Gráfico 1 apresenta os vínculos ativos referentes aos imigrantes procedentes de países parte ou associados ao MERCOSUL. Observa-se que para todos os Estados considerados esses vínculos aumentaram ao longo do período de 2002 a 2014. No caso dos argentinos, paraguaios e bolivianos, essa tendência é ainda mais clara, visto que os vínculos passaram do patamar de 3.000 registros, em 2010, para 7.000, em 2014. É importante destacar, também, o caso dos uruguaios, os quais apresentaram o dobro de vínculos ativos entre 2014, na faixa dos 4.000, e 2002, na faixa dos 2.000 registros.

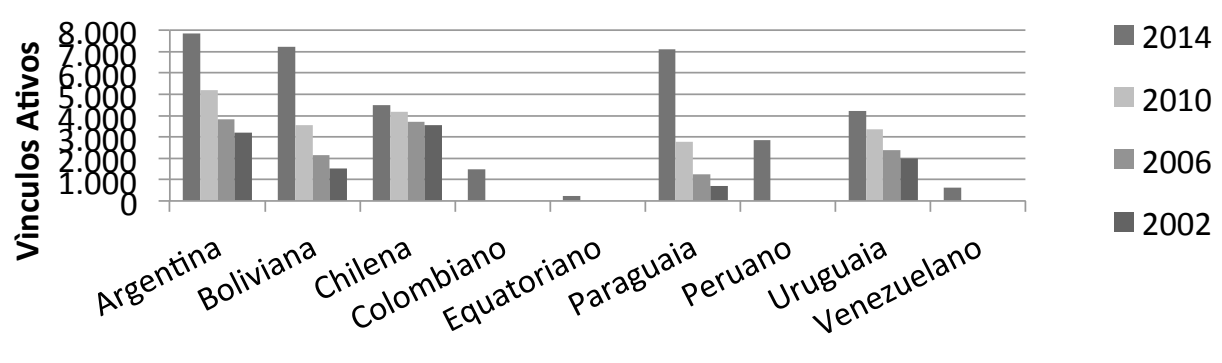

Gráfico 1. Vínculos ativos de imigrantes do MERCOSUL para o Brasil para 2014, 2010, 2006 e 2002.

Fonte: RAIS (2014, 2010, 2006, 2002).

Já a Tabela 2 apresenta os vínculos ativos de imigrantes profissionais do conhecimento, para as três categorias apresentadas na Tabela 1, segundo nacionalidades dos países do MERCOSUL para os anos de 2014, 2010 e 2006. É possível observar um aumento significativo no período considerado, sendo que entre 2006 e 2014 o número total de vínculos mais do que dobrou, passando de 2.723 para 6.112. Destacam-se, entre as nacionalidades com mais imigrantes qualificados, segundo a metodologia adotada, a argentina, chilena e, principalmente, boliviana, que aumentou muito no período, passando de 300 vínculos para 1.394 .

\begin{tabular}{llll}
\hline Nacionalidade & $\mathbf{2 0 1 4}$ & $\mathbf{2 0 1 0}$ & $\mathbf{2 0 0 6}$ \\
\hline Argentina & 1.503 & 1.261 & 1.022 \\
Boliviana & 1.394 & 1.234 & 300 \\
Chilena & 1.059 & 998 & 837 \\
Colombiano & 358 & 0 & 0 \\
Equatoriano & 46 & 0 & 0 \\
Paraguaia & 309 & 243 & 156 \\
Peruano & 733 & 0 & 0 \\
Uruguaia & 535 & 489 & 408 \\
Venezuelano & 175 & 0 & 0 \\
Total & 6.112 & 4.225 & 2.723 \\
\hline
\end{tabular}

Tabela 2. Vínculos ativos de imigrantes profissionais do conhecimento, segundo nacionalidades, para 2014, 2010 e 2006 


\section{SEMINÁRIO DE PESQUISA EM CIÊNCIAS HUMANAS - SEPECH \\ Humanidades, Estado e desafios didático-científicos \\ Londrina, 27 a 29 de julho de 2016}

Fonte: RAIS (2014, 2010, 2006).

Contudo, cabe destacar que apesar do aumento geral nos vínculos ativos desse grupo entre 2014 e 2006, sua participação no total de vínculos registrados variou, passando de 20,45\% em 2006, com 2.723 de 13.315 vínculos, para 22,17\% em 2010, com 4.225 de 19.055 , e finalmente atingindo sua menor participação em 2014, com 6.112 dos 36.065 vínculos ativos de imigrantes com origem nos países do MERCOSUL registrados no mercado de trabalho formal brasileiro.

Além das nacionalidades, os imigrantes profissionais do conhecimento são caracterizados também pelo seu nível de escolaridade e por suas ocupações no mercado de trabalho (MELLO, 2007, FLORIDA, 2004, 2014), sendo que, muitas vezes, essas duas variáveis podem não ser compatíveis, ou seja, o imigrante pode não conseguir uma ocupação equivalente ao seu tempo de estudo, o que pode afetar sua inserção econômica, social, política e até mesmo cultural na sociedade de destino.

O Gráfico 2 apresenta, respectivamente, os vínculos ativos de imigrantes profissionais do conhecimento do MERCOSUL inseridos no mercado de trabalho do Brasil, segundo nível de escolaridade - ensino superior, mestrado e doutorado - entre 2014 e 2006. Em primeiro lugar, destaca-se que o número de vínculos para imigrantes com ensino superior é muito superior ao total de vínculos daqueles com pós-graduação, por isso, torna-se necessário avalia-los separadamente. Assim, é possível notar que os vínculos condizentes com o ensino superior passaram de 2.450 em 2006, para $5.412 \mathrm{em}$ 2014, ou seja, mais do que dobraram em um período de 8 anos, sendo que esse aumento se intensificou, principalmente, após 2010. A respeito do ensino superior é importante ponderar também que a participação masculina aumentou muito em relação à feminina no período passando de 1.439 vínculos em 2.450 (58,7\%), no ano de 2006, para 3.407 em 5.412 (63\%), no ano de 2014.

Já em relação à pós-graduação, é possível analisar a partir do Gráfico 2 que tanto mestrado quanto doutorado apresentaram um aumento nos vínculos ativos para imigrantes profissionais do conhecimento no período, sendo que o mestrado passou de 87 registros, em 2006, para 303 em 2014, enquanto o doutorado passou de 186 para 397, respectivamente.

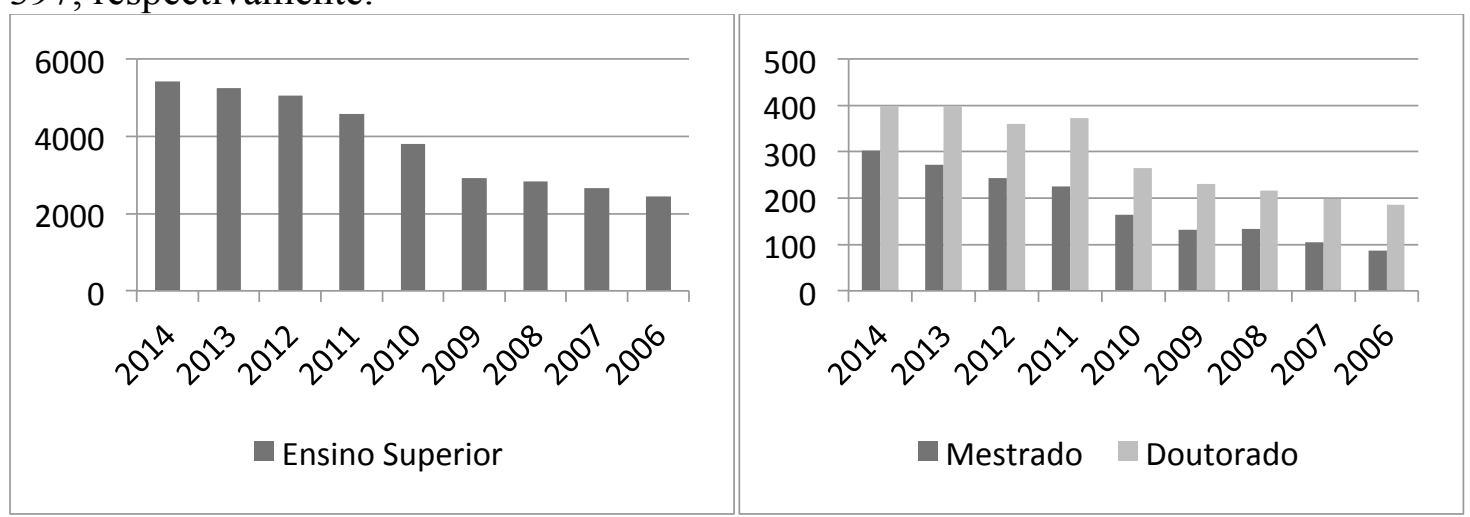

Gráfico 2. Vínculos ativos de imigrantes profissionais do conhecimento do MERCOSUL para o Brasil, segundo escolaridade, entre 2014 e 2006

Fonte: RAIS (2014-2006). 


\section{SEMINÁRIO DE PESQUISA EM CIÊNCIAS HUMANAS - SEPECH \\ Humanidades, Estado e desafios didático-científicos \\ Londrina, 27 a 29 de julho de 2016}

Como discutido inicialmente, essa parcela específica de imigrantes além de apresentar uma alta escolaridade, costuma se inserir em ocupações específicas, centrais para o desenvolvimento e inserção internacional do país e ao mesmo tempo de grande poder social e econômico (FLORIDA, 2014).

O Gráfico 3, apresenta, assim, as três categorias de ocupações consideradas na análise de Florida (2004, 2014) e Mello (2007), no contexto da migração de trabalhadores dos países parte e associados ao MERCOSUL, para o Brasil, no anos de 2014, 2010 e 2006. São elas, o Núcleo Criativo, os Profissionais do Conhecimento e a categoria Outros. No entanto, cabe ter em mente que cada uma delas representa um conjunto diversificado de ocupações discriminadas segundo a CBO-2002. Desse modo, observa-se inicialmente, que as três categorias apresentaram um aumento no número de vínculos ativos entre o período, com destaque para os relativos aos profissionais do conhecimento que passaram de 381 registros em 2006, para 2043, em 2014, ou seja, mais do que quadruplicaram em 8 anos, enquanto as ocupações do núcleo criativo dobraram (de 711, para 1557, entre 2006 e 2014). Em segundo, lugar, é possível destacar a participação da categoria Outros na constituição do grupo de imigrantes profissionais do conhecimento. Entretanto, apesar do aumento no número de vínculos, de 2.723 em 2006, para 6.112, em 2014, nota-se uma queda na participação desse grupo em relação ao total de vínculos relativos a esses imigrantes, a qual passou de 59,9\%, no início do período (1.631 vínculos de 2.723), para 39,8\% em 2010 (1.680 para 4.225) e atingiu sua menor marca em 2014 , com $41 \%$ do total de vínculos ativos registrados (2.512 de 6.112).

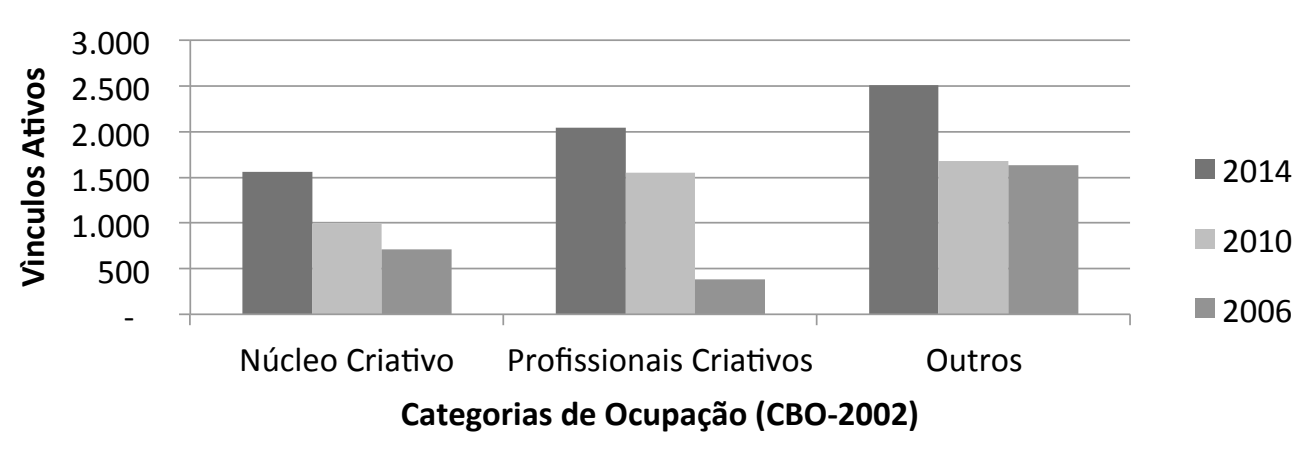

Gráfico 3. Vínculos ativos de imigrantes profissionais do Conhecimento do MERCOSUL para o Brasil, segundo Categoria de Ocupação, para 2014, 2010 e 2006

Fonte: RAIS (2014, 2010, 2006).

Destaca-se, ainda que a categoria Outros é central para o debate acerca dos imigrantes profissionais do conhecimento à medida que é constituída, sobretudo, por profissionais da área de educação, os quais dão condições para a formação dos demais trabalhadores do conhecimento. 


\section{SEMINÁRIO DE PESQUISA EM CIÊNCIAS HUMANAS - SEPECH \\ Humanidades, Estado e desafios didático-científicos \\ Londrina, 27 a 29 de julho de 2016}

\section{CONSIDERAÇÕES FINAIS}

A partir do que foi apresentado até aqui é possível chegar a algumas considerações gerais sobre os fluxos migratórios provenientes dos países parte e associados ao MERCOSUL para o Brasil, especialmente, no que diz respeito aos imigrantes profissionais do conhecimento quando considerados a partir dos vínculos ativos registrados pela RAIS. A primeira delas diz respeito ao aumento geral no número de vínculos ativos registrados para essa parcela particular dos imigrantes, esse processo pode estar relacionado tanto ao aumento dos fluxos migratórios, quanto a uma possível melhora nos registros administrativos obtidos a partir da base de dados da RAIS ao longo dos anos, o que permite uma melhor compreensão da dinâmica do mercado de trabalho nacional, seja em relação aos vínculos de nacionais ou estrangeiros.

A segunda, diz respeito ao importante papel do MERCOSUL enquanto fomentador da integração regional no âmbito da América do Sul, principalmente, quando se leva em conta os acordos e as diretrizes adotadas em prol de uma maior mobilidade dos cidadãos e da garantia de direitos trabalhistas, assistência social e educação dentro dos países parte e associados.

A terceira, por sua vez, diz respeito aos imigrantes profissionais do conhecimento, visto que esse grupo representa uma parcela importante dos trabalhadores que decidem migrar para o Brasil desde países do bloco econômico em questão. Nota-se que dentre as nacionalidades encontradas, os estados parte do MERCOSUL representam uma parcela considerável dos vínculos, no entanto, países como Chile e Bolívia, apenas associados, também contribuem com uma parte significativa dos imigrantes qualificados registrados no Brasil. Ademais, há que se destacar que os vínculos referentes a uma escolaridade igual ou maior ao ensino superior tem acompanhado esse aumento, assim como, os vínculos relativos a ocupações próprias dos trabalhadores do conhecimento, seja no núcleo criativo, nos profissionais do conhecimento ou mesmo na categoria Outros.

\section{REFERÊNCIAS BIBLIOGRÁFICAS}

CASTELLS, M. Technopoles of the world: the making of twenty-first-one century complexes. London, 1996.

;A sociedade em rede. São Paulo: Paz e Terra, 4.ed., v.1, 1999. (A era da informação: economia, sociedade e cultura).

DRUCKER, P. F. Um século de transformações sociais. In: $\mathbf{O}$ melhor de Peter Drucker: a sociedade. São Paulo: Nobel, 2001. (A emergência da sociedade do conhecimento).

FLORIDA, R. (e-book) The rise of the creative class: and how it's transforming work, leisure, community \& everyday life. New York: Basic Books, 2014.

MERCOSUL. Sobre o MERCOSUL. Disponível em: http://www.mercosul.gov.br/saiba-mais-sobre-o-mercosul. Acesso em: 19 mar. 2016. 


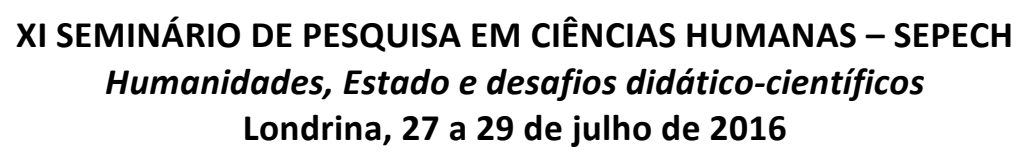

:O MERCOSUL na vida do cidadão. Disponível em: http://www.mercosul.gov.br/o-mercosul-na-vida-do-cidadao. Acesso em: 19 mar. 2016.

MELLO, L. F. Trabalhadores do conhecimento e qualidade do lugar em Campinas - SP. Tese de Doutorado apresentada ao Departamento de Demografia, Instituto de Filosofia e Ciências Humanas da Universidade Estadual de Campinas, 2007.

PALERMO, G.; OLIVEIRA, A.T. e LOPES, J. Conceitos e Notas Metodológicas CGIg/CNIg, RAIS, Censo Demográfico (IBGE). In: A inserção dos imigrantes no mercado de trabalho brasileiro, v.1, n.2, Dossiê Especial. OBMigra, Ed. Especial: Brasília, 2015.

SASSEN, S. The Mobility of Labor and Capital: A Study in International Investment and Labor Flow. Cambridge: Cambridge University Press, 1988. 